\title{
Barriers Affecting Successful Lean Implementation in Singapore's Shipbuilding Industry: A Case Study
}

\author{
Edwin Tan Hock Lai \\ Coventry University, Singapore Campus \\ E-mail: Edwinthl71@gmail.com \\ Florence Ng Jia Yun \\ Ridge View Residential College, \\ National University of Singapore, Singapore \\ E-mail: Florence.ng@nus.edu.sg (Corresponding Author) \\ Ivan C. Arokiam \\ Coventry University, UK \\ E-mail: i.arokiam@coventry.ac.uk \\ John Heng Aik Joo \\ PSB Academy Pte Ltd \\ E-mail: john.heng@psb-academy.edu.sg
}

\begin{abstract}
Lean manufacturing is essential for any company to remain competitive in the global business market. Companies in Singapore's shipbuilding industry encountering fierce competition from overseas shipyards that have lower operating costs have now started to explore lean manufacturing in an attempt to lower their costs and improve the level of manufacturing quality while continuing to deliver high value to customers. Despite the importance of lean manufacturing to the shipping industry, few organizations in Singapore have succeeded in lean implementation. Thus, this study tries to explain the barriers to lean manufacturing as well as provide clarity and guidance to the companies aiming to adopt this practice to strengthen the probability of their success in its implementation.
\end{abstract}

Keywords: lean production, lean manufacturing, lean enterprise, lean implementation, shipbuilding

\subsection{Definition of Lean}

\section{INTRODUCTION}

Lean manufacturing was originally proposed by Taiichi Ohno in 1978 while working for Toyota (Ohno, 1988). In those days, automobile companies were confronted with problems such as over-processing, unnecessary waiting time, superfluous movement of material and people, and defective manufacturing (Mrugalska and Wyrwicka, 2017). The concept of lean manufacturing evolved from this crisis. As the chief of production, Taiichi Ohno decided to revamp Toyota's production process by adopting the Toyota Production System (TPS), a method focusing on the continuous operation to remove all sorts of waste that do not add value to their products. TPS differs from the mass production system (MPS) largely used by automobile manufacturers at that time. MPS involved material resources planning and complex computerized systems for large-scale manufacturing of standardized products with low change over, whereas TPS focused on the elimination of waste by improving the production flow. TPS could also lower the operating costs, improve production quality, and speed up delivery. Such improvement in performance would also mean the ability to operate with fewer employees and less inventory but large increases in productivity.

Despite numerous studies on lean manufacturing, hardly any consensus exists on its definition. This is partly because the concept of lean and the perception of different authors on the subject are constantly evolving, implying that any definition of lean could be valid only at that instant, and any standard and meaningful definition of lean would be dubious (Hines et al., 2004). Thus, lean manufacturing has been defined in various ways and settings by different authors. For instance, Howell (1999) defined lean manufacturing as the production of what customers want with zero inventory and speedy delivery. Kilpatrick (2003) defined lean implementation as an effective technique to identify non-value added activities (waste) and continuously improve and eliminate them. Narasimhan et al. (2006) and Soltan and Mostafa (2015) state that lean implementation uses limited resources to produce maximum value in a competitive environment through waste elimination. Rymaszewska (2014) simply describes the lean implementation as producing more with less input. Phogat (2013) asserted that being lean means eliminating waste and thus reducing costs, improving productivity and efficiency, and delivering added value to customers. Although lean has a broad range of definitions, the common aspect of all these definitions is the elimination of waste to create more value. Thus, from the perspective of shipbuilding operational 
characteristics, we define lean implementation as the ability to provide equal or more value to customers with fewer resources through waste elimination.

Womack and Jones (1996) state that lean production systems are not designed exclusively for the automobile industry. Several other industries, such as aerospace, transportation, building construction, healthcare services, and shipbuilding, can adopt lean implementation (Ward, 2015; Ciobanu and Neupane, 2008). In the following section, we discuss lean implementation with a focus on the Singapore shipbuilding industry.

\subsection{Lean Implementation in Singapore's Shipbuilding Industry}

In Singapore, shipbuilding includes four main sectors, offshore rig building, shipbuilding, ship repair and conversion, and marine support services. Even though their names indicate operational differences, these sectors have similar operational characteristics. For the purpose of this study, we use the overarching term "shipbuilding industry" to include all these four sectors. Compared to other manufacturing industries, such as the automobile industry, shipbuilding has distinct operational characteristics. For instance, in most manufacturing industries, such as the automobile industry, once a model is designed, prototyped, and successfully tested, mass production begins. However, in shipbuilding, the customer specifies what he or she wants, and the shipbuilder delivers the product according to the customer's needs. The production of ships constitutes a builtto-order process, and products are rarely identical. Thus, mass production is not possible in the shipbuilding industry (Bae et al., 2002). The literature has examined the barriers to production in the different manufacturing industries, but such barriers are scarce in the shipbuilding industry. Furthermore, the barriers to production could differ by industry owing to the different operating characteristics. Thus, companies need to have some understanding of shipbuilding operations and the related barriers to production in order to achieve some success in lean implementation.

Over the last four decades, Singapore has achieved world-class status in shipbuilding and it is recognized as one of the world's premier maritime centers (Ong, 2000). The Singapore shipbuilding sector has produced approximately $70 \%$ of the world's jack-up rigs and floating production storage and offloading platforms as well as innumerable types of merchant and support vessels (Watters and Tonami, 2012:110). It has since then contributed significantly to Singapore's economic growth, accounting for approximately $20 \%$ of the total value added in the Singapore Maritime Cluster, and employs approximately $25 \%$ of the total maritime workforce in Singapore (Watters and Tonami, 2012:110). However, as the market environment evolves, the labor-intensive shipbuilding industry finds it increasingly challenging to remain competitive (Ong, 2000). Indeed, local shipyards encounter intense competition from shipyards that have lower labor costs. To stay viable under such intense competition, the industry has to explore ways to lower its operating costs while maintaining or improving the production quality level and continuing to deliver added value to customers. It is thus logical for the Singapore shipbuilding-related companies to explore and adopt the lean concept in order to remain competitive.
The key benefit of lean manufacturing is the elimination of waste that does not add value to products and for which customers do not want to pay (Dwivedi, 2013). Numerous lean manufacturing studies have categorized waste, also known as MUDA in Japanese, into different nonvalue added activities, such as over-production, unnecessary waiting time, unnecessary transportation, over-processing, excessive inventory, unnecessary human labor, superfluous machinery, excessive equipment movement, and production defects (Dubey and Gunasekaran, 2015; Bhasin et al., 2006; Melton, 2005). These activities are considered waste (Howell, 1999) because customers would not want to pay for them (Dwivedi, 2013). Research has found that these nonvalue added activities constitute $95 \%$ of most of the manufacturing operations (Melton, 2005). Consequently, when these activities are identified and minimized or eliminated, customers would dramatically gain higher value. The elimination of waste also benefits companies in terms of lowered operating costs, improved production quality, and superior delivery. Such improvement would also enable companies to operate with fewer employees, less inventory, and consequently increased productivity. Overall, successful lean implementation results in an augmented competitive advantage for organizations and increased value for customers (Dubey and Gunasekaran, 2015; Dwivedi, 2013; Moura and Botter, 2012; Abdulmalek and Rajgopal, 2007; De Treville and Antonakis, 2006). However, lean implementation is not easy to achieve, with few organizations adopting it actually succeeding (Larteb et al., 2015; Jadhav et al., 2014; Bhasin, 2012; Losonci et al., 2011). Not knowing the barriers to lean implementation has been found to be the key reason for the failure of a large number of companies in lean manufacturing (Sharma et al., 2014). Numerous studies have investigated the barriers to lean implementation in various industries, but not many of them related to the shipbuilding industry. Furthermore, the barriers could differ by industry, or even by the company within the same industry. Therefore, it is critical to have some understanding of the shipbuilding operations and related barriers to achieving success in lean implementation.

The remainder of this paper is structured as follows. The next section reviews the pertinent literature and summarizes the studies on the failure of and key barriers to lean implementation. The study then discusses the method used for collecting and analyzing data. The findings of the study are then presented. We conclude the paper with a discussion of the results, the study's limitations, managerial implications, and suggested directions for future research.

\section{REVIEW OF THE LITERATURE 2.1 Lean Implementation Failure}

Lean manufacturing has been implemented in many non-manufacturing industries such as aerospace, healthcare, construction, public sector, and shipbuilding over the last two decades in numerous countries (Williams, 2017; Stone, 2012; Esain et al., 2008), but not many organizations outside Japan have succeeded in lean implementation (Bhasin and Burcher, 2006; Kadri, 2010). To succeed in lean implementation, companies need to identify the reasons for failure in lean implementation and plan and strategize the implementation effectively (Lodgaarda et al., 2016). One of the main aims of this work is to investigate the barriers to 
lean implementation in Singapore's shipbuilding industry.

\subsection{Key Barriers to Lean Implementation in Singapore}

The main reason for the low success in lean manufacturing is the lack of understanding of the barriers to lean implementation (Sharma et al., 2014). A thorough understanding of the key barriers would enable firms to make optimal decisions (e.g., on resource allocations, management, and training) and attain better lean implementation (Zhang et al., 2017) and better results. According to Zhang et al. (2017), the barriers to lean implementation can be grouped into the following ten broad areas by characteristics: organizational culture, knowledge, management, conflict, resources, technology, finance, employees, customers, and past experience. An earlier study by Jadhav et al. (2014) identified 24 lean barriers. From the frequency of the factors addressed in the literature, the three most discussed characteristics are knowledge, management, and culture. We identify these three characteristics as the key barriers and discuss them further in the following sections. An investigation of the key barriers to lean implementation will provide organizations with a better source to access strategies that could increase their success rates in lean implementation.

\subsubsection{Knowledge}

Organizations lacking adequate knowledge of lean manufacturing would find it difficult to succeed in lean implementation. For example for lean implementation, companies commonly adopt lean techniques and tools that help organizations to achieve intended results. To make full use of these lean techniques and tools, employees would first have to understand the aims of each technique and tool as well as how to apply them correctly. Lack of knowledge could arise from the absence of training, limited knowledge of lean benefits, not having implementation expertise, want of implementation skills, not knowing the concepts of lean management, and lack of supervisory skills for senior and middle management (Zhang et al., 2017). The lack of knowledge on how to use these tools and techniques could result in haphazard application jeopardizing lean implementation severely (Kumar and Kumar, 2014). Thus, managers and workers across organizations have to be equipped with the requisite knowledge if the lean implementation has to succeed (Jadhav et al., 2014; Čiarnienė and Vienažindienè, 2013; Cheah et al., 2012; Nordin et al., 2010).

The know-how of lean implementation can help companies understand the potential benefits of lean manufacturing. A good understanding of the potential benefits of lean implementation, such as increased flexibility and reduced re-work, would help employees work toward the common objective of lean implementation. In contrast, lack of understanding of its potential benefits would hinder lean implementation (Bhasin, 2012; Nordin et al., 2010; Mann, 2009).

According to Staudacher and Tantardini (2008), many organizations have yet to properly understand the lean concept's applicability. Specifically, some of them still consider the concept applicable only to Japan, and not suitable for other countries, or suitable only for large setups or some particular industries where lean implementation would require enormous investment (Bakås et al., 2011). According to Mann (2009), organizations often misconstrue lean implementation as a cost-reduction initiative that once implemented will gain them permanent cost benefits. Therefore, organizations that fail to experience immediate cost savings are frequently disappointed and change the direction of their lean efforts. To succeed in lean implementation, organizations should adopt a consistent approach to the transformation process. Several organizations having insufficient knowledge of lean implementation have chosen not to focus on all of its aspects and have thus not been able to realize its potential benefits; some organizations have given up on lean implementation altogether (Kumar and Kumar, 2014; Mirzaei, 2011; Nordin et al., 2010). Further to the above investigations, we have the following hypothesis:

Hypothesis 1 (H1): Knowledge is associated with lean implementation failure.

\subsubsection{Management}

The barriers to lean implementation, such as lack of vision and strategic direction, and insufficient management time, commitment, support, and communication between management and employees, could impede the success of lean manufacturing (Zhang et al., 2017; Kumar and Kumar, 2014). In this study, management includes any employee performing managerial roles in the organization, such as the top leadership, that is, the chief executive officer, managing director, or executive director (Zhang et al., 2012; Houshmand and Jamshidnezhad, 2006).

For the success of any organizational goal, the top management should have the vision, aproach, and direction (what, why, when, where, who, and how) to keep the implementation plan on track (Zhang et al., 2012; Houshmand and Jamshidnezhad, 2006). This is echoed by Taleghani (2010), who reported that top management plays a crucial role in lean implementation. According to Mann (2009), management support for establishing the optimal implementation conditions contributes $80 \%$ of a successful implementation. Similarly, Poksinska et al. (2013), while investigating lean leaders, found lean leadership to be a key factor to lean program implementation and sustainability. Indeed, the transformation to a lean enterprise cannot be achieved without continuous effort from senior leadership in coordinating, communicating, and leading the strategic implementation plan (Grove et al., 2010). However, Dombrowski and Mielke (2013) caution that the main factor that adds value to a process or product is not lean leadership, but rather worker contribution. Indeed, lean leaders create the environment for value creation and enable the workers to add value.

In addition to the governance structure, success can be achieved through the frequent support of management in the implementation and by making everyone accountable and committed to the program (Mann, 2009). Since lean implementation emphasizes the need for a top-down approach, the management team would have to commit sufficient time to support the program. With management support for all in the organization and endorsement of changes, such as the procedures, processes, and functional roles in lean implementation, interest would be created and 
the required autonomy would be provided to employees for implementation (Boyer and Sovilla, 2003). Top management "leadership by example" would yield great advantages in lean practices as workers witness, understand, and "buy-in" to the process (Wong and Wong, 2011). Although workers may notice weaknesses in their processes, they may not have the knowledge, authority, and/or resources to deal effectively with them; that is, management commitment and support are essential for improvement (Dombrowskiet and Mielke, 2013). Organizations lacking in management commitment and support in lean implementation programs would also tend to experience a high rate of training and resourceallocation issues (Jeyaraman and Kee 2010). Thus, employees may feel that the management does not care about their improvement, and that their efforts are not recognized. All the above factors have led to failures in lean implementation (Worley and Doolen, 2006; Wong and Wong, 2011; Mirzaei, 2011; Dombrowski and Mielke., 2013). Numerous authors have found that for the success of lean transformation, management should commit themselves to provide the direction and required resources, acquire new and effective ideas and technologies, and provide appropriate training to the employees to better understand the lean methodology and ensure open lines of communication concerning implementation (Achanga et al., 2006; Grove et al., 2010; Sharma et al., 2014).

Failure of the organization to communicate its vision, strategy, and direction in lean implementation to employees constitutes another common organizational oversight. The lack of communication or clarification on the need for change or preparation for future challenges would frustrate and confuse the employees involved. This would also substantially increase the doubts, tensions, and job security concerns (Scherrer-Rathje et al., 2009). Moreover, failure to communicate the gains from lean implementation across the organization would result in the unawareness of other functions and thus non-attainment of "buy-in" and support (Jadhav et al., 2014). In line with these observations, we have the following hypothesis:

Hypothesis 2 (H2): Management is associated with lean implementation failure.

\subsubsection{Management}

Bhasin et al. (2006) found that, besides focusing on reducing waste, lean implementation changes the culture of an organization. Several studies have shown that organizations failing to build a lean improvement culture, also known as a "no-blame culture," with attitudes and behaviors that strive for perfection, would perform poorly in lean implementation (Dombrowski and Mielke, 2013; Kadri, 2010; Robinson and Schroeder, 2009; Krijnen, 2007). As Urban (2015) states, many organizations hold the mistaken notion that lean does not require a change in culture in order to continually improve. Hence, senior leadership tends to overlook the importance of building a corresponding culture (Dombrowski and Mielke, 2013). A previous study by Crute et al. (2003) found that organizations embracing the noblame culture inculcated a high degree of autonomy among their employees, who were empowered and motivated to participate in lean implementation, and also were likely to provide suggestions in areas of improvement (Čiarnienè and Vienažindienè, 2012). Employees also tended to assume ownership and perform as needed, rather than act only when instructed to do so. This empowerment has been shown to significantly speed up the rate of change and improvement (Crute et al., 2003). In contrast, employees could be reluctant to implement lean ideas, fearing to be blamed for unsuccessful attempts as well as for wasting time and resources in organizations, with the result that their actions could be more closely scrutinized by senior management.

The diversity in culture between the employees in an organizations also poses a challenge to pursuing lean implementation (Cudney and Elrod, 2010). In the present multinational organizations, employees work alongside colleagues, co-workers, superiors, contractors, and suppliers from different countries as well as with different beliefs, attitudes, behaviors, and languages. Cultural diversity can impede coordination and cooperation, result in conflicts, and thus hinder lean implementation efforts. It is thus critical for managers and employees to possess the ability to operate effectively in diverse environments (Achanga et al., 2006). Following the above investigations, this study hypothesizes as follows:

Hypothesis 3 (H3): Culture is associated with lean implementation failure.

\subsection{Conceptual Framework}

Figure 1 illustrates the framework of this study. It shows the relationship between the purported key barriers and the lean implementation.

\section{$\underline{\text { Key Barriers }}$}

\section{Knowledge (Hypothesis 1) Management (Hypothesis 2) Organizational Culture (Hypothesis 3)}

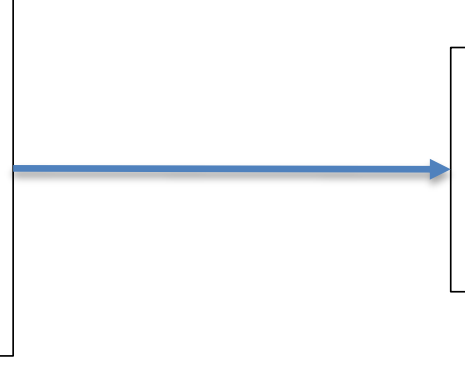

Lean Implementation Failures

Figure 1 Conceptual framework of the relationship between the purported key barriers and the lean implementation. 


\section{METHODOLOGY}

To assess the effect of knowledge, management, and the organizational culture factors on lean implementation failures, we utilize a quantitative research design. This quantitative method facilitates the collection of quantitative data required to further test the hypotheses (Newman et al., 1998).

The measures used in this study were adapted from prior studies (Urban, 2015; Mirzaei, 2011; Salem et al., 2016; Vlachos and Siachou, 2018; Raines, 2018) and modified to fit our research context. From two rounds of pretesting, we developed the questionnaire used for this study. In the first round, we converted the questionnaire into an online format via Google Form and sent the survey link to 30 randomly selected employees via email. Their email addresses were obtained from the organization's email address book and the subcontractor's emailing list. The first round of pre-testing helped us to verify the clarity of the questions asked and the effectiveness of the measurements and scales used. We then edited the questionnaire from the feedback obtained after the first round of pre-testing. We then used this edited questionnaire in the second round of pre-testing on 10 employees. In this round, we interviewed 10 random employees (Scheuren, 2004: 47). This method gave us the respondents' reactions, such as their doubts and any other misunderstandings. The respondents were further probed to clarify their observations as well as any other point on the questionnaire upon its completion. The suggested changes from the pre-test were then incorporated into the final questionnaire. A reliability test was also conducted to test the reliability of the developed questionnaire.

The sampling frame included the employees currently working in the Singapore shipbuilding industry since those with no experience would not have enough knowledge to answer questions about the industry, its organizational culture, and management. This study chose a major shipyard to represent the shipbuilding industry in Singapore. Owing to sensitivity issues, we do not name the organization examined in this study. Thus, for the purpose of this study, we simply name the organization studied as "Sinshipbuilding." We chose this organization because it is one of the earliest shipbuilding companies established after the island gained independence in 1965. This company has grown from a small company to become a large and dynamic one over the last four to five decades. Today, Sinshipbuilding has established a truly global footprint. In Singapore, this company operates with a daily workforce of 3,000 local and 7,000 foreign employees on average, consisting of both direct employees and workers of about 120 small and medium enterprise subcontractors. This is a relatively large organization, representing a large percentage of the shipbuilding industry, contributing significantly to the maritime cluster growth of Singapore.

From an examination of numerous studies on similar topics, such as Bhasin (2012) and Salem et al. (2016), we find that a sample size of 68 to 330 respondents is appropriate for this type of survey research. Taking this as a guide, we send survey invitations to a total of 250 respondents. Since a member of the population of interest in this study can be known through the organization's email address book, including that of its subcontractors, we choose non-probability sampling for this survey. We thus distributed Google Form questionnaire survey links to 250 employees, that is, to the supervisors, technicians, foremen, engineers, and managers of Sinshipbuilding and its contractors from within the total 536 email addresses available. From the 250 survey invitations sent, we received back a total of 96 completed questionnaires. This represented a response rate of $38.4 \%$, which can be considered adequate for email surveys. We then analyzed these 96 usable responses using SPSS (version 26), measuring the reliability of the questionnaire using a reliability test and analyzing the data and testing the proposed hypotheses through regression analyses (Pallant, 2005).

\section{DATA ANALYSIS AND RESULTS 4.1 Reliability and Validity Analysis}

We analyzed the data collected via the questionnaires using the Cronbach's alpha test in SPSS (version 26) to ensure reliability (Tavakol and Dennick, 2011), and examined the reliability using Cronbach's alpha values for each variable. As the following table shows, all the variables are valued above 0.70 , a commonly accepted level, indicating high internal consistency. Therefore, we deem the questionnaire reliable. The results of the reliability test are shown in Table 1.

Table 1 Reliability of measurement items

\begin{tabular}{lcc}
\multicolumn{1}{c}{ Dimension } & Cronbach's Alpha & No. of Items \\
\hline Knowledge (Hypothesis 1) & .94 & 15 \\
Management (Hypothesis 2) & .94 & 10 \\
Organizational Culture (Hypothesis 3) & .94 & 9 \\
\hline Total & .96 & 34 \\
\hline Dependent Variable: Lean Implementation Failure & & 1 \\
\hline
\end{tabular}




\subsection{Collinearity}

We used multiple regression analysis to test the hypotheses. Before to the analysis, correlation analysis is conducted to assess multicollinearity in the model's independent variables.

This is done to ensure that the assumption used in the linear regression analysis is not violated. As shown in Table 2, the tolerance and Variance Inflation Factor (VIF) values of all the independent variables are within the range (tolerance $>.10$ and VIF < 10), indicating no severe multicollinearity issues in the regressors (Pallant, 2005).

Table 2 Correlation analysis

\begin{tabular}{ccc}
\hline Independent Variables & Tolerance & VIF \\
\hline Knowledge & .16 & 6.47 \\
Management & .15 & 6.87 \\
Organizational Culture & .15 & 6.53 \\
\hline
\end{tabular}

*Dependent variable: Lean implementation failure

\subsection{Pearson Correlation Analysis}

Of the three independent variables (knowledge, management, and organizational culture), knowledge has the highest correlation with the dependent variable, that is, lean implementation failure, followed by management $(r=.77, p$ $<.001)$ and organizational culture $(\mathrm{r}=.76, \mathrm{p}<.001)$. All three variables exhibited a significant relationship with lean implementation failure.

\subsection{Hypotheses Testing}

To test the hypotheses on the barriers of knowledge (H1), management (H2), and organizational culture (H3), we performed a regression analysis using the SPSS (version 26). The regression analysis results are presented in Table 3 . All the three variables show a significant relationship with lean implementation failure $(\mathrm{H} 1-\mathrm{H} 3)$, with $\mathrm{p}$ values $>.05$.

H1 examined the influence of knowledge on lean implementation failure. It is supported, with beta $=.79$ and $p$ value $>.00$, which is significant. $\mathrm{H} 2$ examined the influence of management on lean implementation failure. This is also supported, with beta $=.77$ and $\mathrm{p}>.00 \mathrm{H} 3$ examined the influence of organizational culture on lean implementation failure. It is supported, with beta $=.76$ and $p>.00$.

Table 3 Regression analysis results

\begin{tabular}{cccc}
\hline Independent Variable & B & Beta & t-value \\
\hline Knowledge & 1.05 & .79 & $12.48^{* * *}$ \\
Management & .99 & .77 & $11.70^{* * *}$ \\
Organizational Culture & .85 & .76 & $11.39^{* * *}$ \\
\hline
\end{tabular}

\subsection{An Integrated Model for Lean Implementation Failure}

From the multiple regression analysis results, all the variables exhibited a significant influence on lean implementation failure. The R square value of $65 \%$ indicates that $65 \%$ of the failure in lean implementation's variance can be explained by these three variables $(\mathrm{F}=56.13, \mathrm{p}<.001)$.
Table 4a Regression analysis results

\begin{tabular}{l|l}
\hline $\mathbf{R}$ & .80 \\
\hline $\mathbf{R}$ Square & .65 \\
\hline Adjusted R Square & .64 \\
\hline
\end{tabular}

Table 4b Regression analysis results

\begin{tabular}{ccccc}
\hline & $\begin{array}{c}\text { Sum of } \\
\text { Squares }\end{array}$ & df & $\begin{array}{c}\text { Mean } \\
\text { Square }\end{array}$ & F \\
\hline Regression & 46.23 & 3 & 15.41 & 56.13 \\
Residual & 25.26 & 92 & .275 & \\
\hline Total & 71.50 & 95 & & \\
\hline
\end{tabular}

\section{DISCUSSION}

The shipbuilding industry has played an integral role in Singapore's maritime cluster, contributing significantly to the country's economic growth during the past four decades. In recent years, Singapore's shipbuilding industry has been facing intense competition from companies in the developing countries who have lower operating costs. Thus, to remain relevant in the market, the Singapore shipbuilding industry has been exploring lean manufacturing to increase their operational efficiency, that is, by providing higher value to customers while keeping their costs to a minimum. Although numerous industries have acknowledged the lean concept, relatively few companies have been able to successfully implement them locally. Our findings elucidate some of the specific issues that have contributed to the failure of lean implementation in Singapore's shipbuilding industry. With these results, we believe that appropriate steps can be taken to reduce the barrier effects and thus substantially augment the probability of successful lean implementation in the industry.

From our findings, for lean implementation to succeed, all the three factors investigated herein, that is, knowledge, management, and organizational culture are vital. We will discuss these factors in detail in the following sections.

\subsection{Knowledge}

Our findings indicate that knowledge is closely related (beta $=.79$ ) to lean implementation failure. Knowledge can result from the skills and know-how to implement lean manufacturing, as well as from understanding the key benefits of lean manufacturing. Our results corroborate the findings of studies such as Kumar and Kumar (2012), Houshmand and Jamshidnezhad (2006), and Jadhav et al. (2014). An organization with a high percentage of untrained employees at all job levels in terms of lean implementation would certainly be ill-equipped to proceed toward lean implementation, not to mention its success in those efforts (Kumar and Kumar, 2012). The lack of knowledge in lean concepts in terms of benefits can lead to failure in lean implementation. Indeed, limited understanding of the potential benefits of the lean concept has contributed to the mistaken belief that it is not appropriate for the shipbuilding industry, to result in employees not motivated to invest in lean implementation. 


\subsection{Management}

For successful implementation of the lean concept, support of the top management is essential (Zhang et al., 2012; Houshmand and Jamshidnezhad, 2006). An interesting finding showed the respondents believing that the management was not committed to supporting successful lean implementation. Without a full commitment from the management, especially the top/senior leadership of the organization, the decision to execute implementation would be delayed, financial support would be lacking, and the various resources required for successful implementation would not be available (Kumar and Kumar, 2012). In such an environment, employees will not be motivated to explore new ideas for improvement (Scherrer-Rathje et al., 2009; Jadhav et al., 2014). Thus, lack of management involvement is a crucial factor contributing to the failure in lean implementation.

Our findings are in line with those of Bhasin (2012), who found that team leaders should be empowered to monitor lean implementation. Survey questions on employee empowerment found the majority of respondents feeling not empowered enough to suggest improvement in work processes. The respondents also felt that they were not encouraged to make decisions on how to implement changes that could increase value in their daily tasks. To find the better ways to accomplish tasks with higher value, employees need to be given the flexibility to experiment. Such empowerment would allow them to be proactive and explore the potential of lean application in their area of work (Jadhav et al., 2014).

\subsection{Organizational Culture}

Our findings support Crute et al. (2003) and Čiarnienè and Vienažindienè (2012), who reported that the failure to engage the workforce and support them in achieving and maintaining the lean improvement culture does not encourage employee participation in lean implementation (Crute et al., 2003; Čiarniene et al., 2012). In an organization that does not have a conducive culture for lean implementation, employees would believe that they will be penalized if the ideas they experiment with failed and that they would have no support for experimentation. Such an environment would discourage lean implementation.

Company culture is another organizational factor important for the shipbuilding industry in Singapore. This is particularly true for the Singapore shipbuilding industry, which is both labor-intensive and heavily dependent on foreign labor supply. Thus, the employees at all levels of the organization consist of people from multiple countries, such as India, China, the Philippines, and Malaysia, leading to natural diversity in culture and language. Cultural barriers are a great challenge to effective participation and hamper the inclusion of all employees in improved implementation (Cudney and Elrod, 2010).

\section{MANAGERIAL IMPLICATIONS}

Organizations can consider establishing a lean improvement system in which lower-level employees, such as workers, supervisors, technicians, foremen, and engineers, can offer suggestions for improvement to managers. The managers will then discuss and review these suggestions with senior management. Then, the management will decide, approve, and provide necessary financial and other support for the proposed ideas if they deem them feasible. Thus, employees would be motivated to explore new ideas that could improve the day-to-day performance if they believe that the management will speedily review and support their ideas with necessary financial and other resources once they acknowledge the potential of the ideas. Managers will also be able to monitor the trial results and determine whether they could meet or even exceed the existing procedures' expected results. Further approval could then be given to amending the procedures and additional resources could be allocated for mass implementation, should the ideas prove worthwhile during the trial. Management can also communicate such success through the system and reach out to all employees to further encourage involvement. With this system in place, the organization would have moved toward creating a lean improvement culture that would support as well as sustain improvement (Achanga et al., 2006).

Organizations could consider investing and subscribing to a structured training program in order to equip different levels of employees with the requisite lean knowledge, understanding, and skills. With such training, various employees at different levels would be able to utilize their lean knowledge and effectively apply lean tools across the organization. Managers will then be empowered to provide effective supervision of lean implementation and obtain desired outcomes.

\section{CONCLUSION}

In conclusion, the shipbuilding industry has played an important role in Singapore's maritime cluster, contributing significantly to the country's economic growth during the last four decades. However, this dynamic and highly laborintensive industry has been facing increasing competition from companies in both developed and developing countries that have greater labor supply and lower operating costs. To remain relevant in the market, the Singapore shipbuilding industry has been exploring ways to increase its operational efficiency by providing higher value to customers and tightly controlling its costs. Lean manufacturing is the methodology that this industry uses to achieve these goals. The present study has attempted to elucidate the barriers to lean implementation and identify what could be done to increase the probability of success in the shipbuilding industry. This study is not without limitations. We used a sample size of 96 small- and medium-sized subcontractors from one major Singapore shipbuilding organization (having over 100 smalland medium-sized subcontractors); this may be insufficient to represent the Singapore shipbuilding industry as a whole, and hence the current findings should be interpreted with care. Future studies need to replicate this work using a larger sample size from multiple shipbuilding organizations in Singapore. Furthermore, this study is limited to Singapore's context and hence cannot be generalized to the global shipping industry. Future studies on the shipping industry should investigate the effects of culture on lean implementation from a global perspective. Nevertheless, this study is beneficial in that it provides the Singapore shipbuilding industry with information on the potential of lean concepts to achieve their desired goals. It also provides pertinent information on the possible barriers to the success of lean implementation and some measures that management 
can implement to overcome these barriers. To eliminate their weaknesses and increase the probability of success, shipbuilding providers must identify the barriers to the success of lean implementation and overcome them.

\section{ACKNOWLEDGMENT}

Florence $\mathrm{Ng}$ would like to acknowledge that some parts of this work published in the paper were carried out at Coventry University, Singapore Campus (PSB Academy).

\section{REFERENCES}

Abdulmalek, F.A., and Rajgopal, J. (2007). Analyzing the benefits of lean manufacturing and value stream mapping via simulation: a process sector case study. International Journal of Production Economics 107 (1), pp. 223 - 236.

Achanga, P., Shehab, E., Roy, R., and Nelder, G. (2006). Critical success factors for lean implementation within SMEs. Journal of Manufacturing Technology 17 (4), pp. 460 - 471.

Aurelio, D., Grilo, A., and Cruz-Machado, V. (2011). A framework for evaluating lean implementation appropriateness. Industrial Engineering and Engineering Management (IEEM), IEEE International Conference, pp. 779 - 783.

Bae, Y.H., Song, S., Um, M.J., Lee, D.H., and Hobday, M. (2002). Case study on technological innovation of Korean firms. Research Report, pp. 1 - 189.

Bakås, O., Govaert, T., and Van Landeghem, H. (2011). Challenges and success factors for implementation of lean manufacturing in European SMES. 13th International Conference on the Modern Information Technology in the Innovation Processes of the Industrial Enterprise, Trondheim, Norway, pp. 1 - 11. Tapir Academic Press.

Bhasin, S. (2012). An appropriate change strategy for lean success. Management Decision 50 (3), pp. 439 - 458.

Bhasin, S., and Burcher, P. (2006). Lean viewed as a philosophy. Journal of Manufacturing Technology Management 17 (1), pp. $56-72$.

Boyer, M., and Sovilla, L. (2003). How to identify and remove the barriers for a successful lean implementation. Journal of Ship Production 19 (2), pp. 116 - 120.

Cheah, A.C.H., Wong, W.P., and Deng, Q. (2012). Challenges of lean manufacturing implementation: A hierarchical model. Proceedings of the 3rd 2012 International Conference on Industrial Engineering and Operations Management, Istanbul, pp. $2091-2099$.

Čiarnienè, R., and Vienažindienè, M. (2012). Lean manufacturing: theory and practice. Economics and Management 17 (2), pp. $726-732$.

Čiarnienė, R., and Vienažindienė, M. (2013). Lean manufacturing implementation: the main challenges and barriers. Management Theory and Studies for Rural Business and Infrastructure Development 35 (1), pp. 43 - 49.

Ciobanu, I.C., and Neupane, G.P. (2008). Phase-based Project Management at Aker Yards Langsten: A Lean Shipbuilding Perspective (Master's Thesis). HøgskoleniMolde, pp. 7 151.

Crute, V., Ward, Y., Brown, S., and Graves, A. (2003). Implementing lean in aerospace - challenging the assumptions and understanding the challenges. Technovation 23 (12), pp. $917-928$.

Cudney, E., and Elrod, C. (2010). Incorporating lean concepts into supply chain management. International Journal of Six Sigma and Competitive Advantage 6 (1-2), pp. 12 - 30.

De Treville, S., and Antonakis, J. (2006). Could lean production job design be intrinsically motivating? Contextual, configurational, and levels-of-analysis issues. Journal of Operations Management 24 (2), pp. 99 - 123.
Dombrowski, U., and Mielke, T. (2013). Lean leadershipfundamental principles and their application. Procedia CIRP 7, pp. $569-574$

Dubey, R., and Gunasekaran, A. (2015). Agile manufacturing: framework and its empirical validation. International Journal of Advanced Manufacturing Technology, 76, pp. 2147 - 2157.

Dwivedi, A. (2013). Historical development of quality concept: lean manufacturing (LM)-today and tomorrow. International Journal of Innovative Research and Studies (IJIRS) 2 (10), pp. $568-594$.

Esain, A., Williams, S., and Massey, L. (2008). Combining planned and emergent change in a healthcare lean transformation. Public Money and Management 28 (1), pp. $21-26$.

Grove, A.L., Meredith, J.O., Macintyre, M., Angelis, J., and Neailey, K. (2010). UK health visiting: challenges faced during lean implementation. Leadership in Health Services 23 (3), pp. $204-218$.

Hines, P., Holweg, M., and Rich, N. (2004). Learning to evolve: a review of contemporary lean thinking. International Journal of Operations \& Production Management 24 (10), pp. 994 1011.

Houshmand, M., and Jamshidnezhad, B. (2006). An extended model of design process of lean production systems by means of process variables. Robotics and Computer-Integrated Manufacturing 22 (1), pp. $1-16$.

Howell, G.A. (1999). What is lean construction-1999? Proceedings of the $7^{\text {th }}$ International Group for Lean Construction Conference, University of California, Berkeley, CA, USA, pp. $2-10$.

Jadhav, R.J., Mantha, S.S., and Rane, B.S. (2014). Exploring barriers in lean implementation. International Journal of Lean Six Sigma 5 (2), pp. 122 - 148.

Jeyaraman, K., and Kee, T.L. (2010). A conceptual framework for critical success factors of lean Six Sigma: implementation on the performance of electronic manufacturing service industry. International Journal of Lean Six Sigma 1 (3), pp. 191 - 215.

Kadri, K. (2010). Cultural and habitual features and the implementation of lean principles in companies: mapping out the research. Proceedings of the Lean Advancement Initiative 5th LAI/EdNet Lean Educator Conference, Daytona Beach, Florida, pp. $19-21$

Kelley, K., Clark, B., Brown, V., and Sitzia, J. (2003). Good practice in the conduct and reporting of survey research. International Journal for Quality in Health Care 15 (3), pp. $261-266$.

Kilpatrick, J. (2003). Lean principles. Utah Manufacturing Extension Partnership, 68, pp. 1 - 5.

Krijnen, A. (2007). The Toyota way: 14 management principles from the world's greatest manufacturer. Action Learning: Research and Practice, 4 (1), pp. 109 - 111.

Kumar, R., and Kumar, V. (2014). Barriers in implementation of lean manufacturing system in Indian industry: A survey. International Journal of Latest Trends in Engineering and Technology 4 (2), pp. $243-251$.

Larteb, Y., Haddout, A., Benhadou, M., Manufacturing, L., Yang, C., Yeh, T., and Valero, M. (2015). Successful lean implementation: the systematic and simultaneous consideration of soft and hard lean practices. International Journal of Engineering Research and General Science 3 (2), pp. $1258-1270$.

Losonci, D., Demeter, K., and Jenei, I. (2011). Factors influencing employee perceptions in lean transformations. International Journal of Production Economics 131 (1), pp. 30 - 43.

Lodgaard, E., Ingvaldsen, J. A., Aschehoug, S., \& Gamme, I. (2016). Barriers to continuous improvement: perceptions of top managers, middle managers and workers. Procedia CIRP 41, pp. 1119-1124.

Mann, D. (2009). The missing link: lean leadership. Frontiers of Health Services Management 26 (1), pp. 15 - 26. 
Melton, T. (2005). The benefits of lean manufacturing: what lean thinking has to offer the process industries. Chemical Engineering Research and Design 83 (6), pp. $662-673$.

Mirzaei, P. (2011). Lean Production: Introduction and Implementation Barriers with SMEs in Sweden (Master's Thesis). Jönköping School of Engineering.

Moura, D.A., and Botter, R.C. (2012). Can a shipyard work towards lean shipbuilding or agile manufacturing?. In Rizzuto and Soares (Eds.), Sustainable Maritime Transportation and Exploitation of Sea Resources, pp. $559-565$.

Mrugalska, B., and Wyrwicka, M.K. (2017). Towards lean production in industry 4.0. Procedia Engineering 182, pp. $466-473$.

Narasimhan, R., Swink, M., and Kim, S.W. (2006). Disentangling leanness and agility: an empirical investigation. Journal of Operations Management 24 (5), pp. 440 - 457.

Newman, I., Benz, C.R., and Ridenour, C.S. (1998). QualitativeQuantitative Research Methodology: Exploring the Interactive Continuum. SIU Press, Ohio.

Nordin, N., Md Deros, B., and Wahab, D.A. (2010). A survey on lean manufacturing implementation in Malaysian automotive industry. International Journal of Innovation, Management and Technology 1 (4), pp. $374-380$.

Ohno, T. (1988). Toyota Production System: Beyond Large-scale Production. Productivity Press, Portland, Oregon.

Ong, P. K. (2000). Sustaining Singapore Marine Industry's Premier Position: A Strategic Review (Doctoral Dissertation). Massachusetts Institute of Technology.

Phogat, S. (2013). An introduction to applicability of lean in shipbuilding. International Journal of Latest Research in Science and Technology 2 (6), pp. 85 - 89.

Poksinska, B., Swartling, D., and Drotz, E. (2013). The daily work of lean leaders: lessons from manufacturing and healthcare. Total Quality Management \& Business Excellence 24 (7-8), pp. $886-898$.

Raines, J.J. (2018). Perceived Barriers to the Successful Implementation of Lean in Behavioral Healthcare and Perceptions of Implementation Success (Doctoral Dissertation). Wilmington University.

Robinson, A.G., and Schroeder, D.M. (2009). The role of front-line ideas in lean performance improvement. Quality Management Journal 16 (4), pp. 27 - 40.

Rymaszewska, A.D. (2014). The challenges of lean manufacturing implementation in SMEs. Benchmarking: An International Journal 21, pp. 987 - 1002.

Scherrer-Rathje, M., Boyle, T.A., and Deflorin, P. (2009). Lean, take two! Reflections from the second attempt at lean implementation. Business Horizons 52 (1), pp. 79 - 88.

Scheuren, F. (2004). What Is a Survey? American Statistical Association, Washington, DC, USA.
Sharma, V., Dixit, A.R., and Asim, M. (2014). Analysis of barriers to lean implementation in machine tool sector. International Journal of Lean Thinking 5 (1), pp. 5 - 25.

Soltan, H., and Mostafa, S. (2015). Lean and agile performance framework for manufacturing enterprises. Procedia Manufacturing 2, pp. 476 - 484.

Staudacher, A.P., and Tantardini, M. (2008). Lean production implementation: a survey in Italy. Dirección y Organización (35), pp. $52-60$.

Stone, K.B. (2012). Lean transformation: organizational performance factors that influence firms' leanness. Journal of Enterprise Transformation 2 (4), pp. $229-249$.

Taleghani, M. (2010). Key factors for implementing the lean manufacturing system. Journal of American Science 6 (7), pp. $287-291$.

Tavakol, M., and Dennick, R. (2011). Making sense of Cronbach's alpha. International Journal of Medical Education 2, pp. 53 -55 .

Trochim, W.M., and Donnelly, J.P. (2001). Research Methods Knowledge Base, Cornell University, New York.

Urban, W. (2015). The lean management maturity self-assessment tool based on organizational culture diagnosis. ProcediaSocial and Behavioral Sciences 213, pp. 728 - 733.

Vlachos, I., and Siachou, E. (2018). An empirical investigation of workplace factors affecting lean performance. International Journal of Productivity and Performance Management 67 (2), pp. $278-296$.

Ward, S.A. (2015). Critical Success Factors for Lean Construction (Doctoral Dissertation). The University of Dundee.

Watters, S., and Tonami, A. (2012). Singapore: An Emerging Arctic Actor. Arctic Yearbook 2012, pp. $105-114$.

Womack, J.P., and Jones, D.T. (1996). Beyond Toyota: how to root out waste and pursue perfection. Harvard Business Review 74 (5), pp. $140-158$.

Wong, Y.C., and Wong, K.Y. (2011). Approaches and practices of lean manufacturing: the case of electrical and electronics companies. African Journal of Business Management 5 (6), pp. $2164-2174$.

Worley, J.M., and Doolen, T.L. (2006). The role of communication and management support in a lean manufacturing implementation. Management Decision 44 (2), pp. 228 - 245.

Zhang, Q., Irfan, M., Khattak, M.A.O., Abbas, J., Zhu, X., and Shah, M.S. (2012). Critical success factors for successful lean Six Sigma implementation in Pakistan. Interdisciplinary Journal of Contemporary Research in Business 4 (1), pp. 117 -124 .

Zhang, L., Narkhede, B.E., and Chaple, A.P. (2017). Evaluating lean manufacturing barriers: an interpretive process. Journal of Manufacturing Technology Management 28 (8), pp. 1086 -1114 .

Edwin Tan Hock Lai is a continuous improvement manager in a major shipbuilding firm in Singapore. He was a student at the Coventry University (Singapore Campus) where this work is produced in the final semester. He had since obtained his MSc in Engineering Business Studies from the University.

Florence Ng Jia Yun (Dr) is a lecturer at Ridge View Residential College, National University of Singapore. She was previously teaching at Coventry University (Singapore Campus) where this work was conducted. She obtained her Ph.D from Monash University, Australia specializing in Business Marketing. She has published several International Journals and presented several papers at International Conferences in South Korea and Australia. Her primary areas of interest include Ecommerce, Consumer behavior, Research Methodology and Lean Implementation.

Ivan C. Arokiam (Dr) is an Assistant Professor and course director for Part Time BSc Engineering students at Coventry University. Ivan's areas of expertise include Agile/Lean manufacturing, Production planning, Manufacturing process and Simulation. He has taught both post and undergraduate students in these areas and also carried out applied research around production optimization. Ivan's applied research has been mainly through ERDF projects and he was also the principal investigator/project director of one of the main grant - Performance Improvement Initiative. 
John Heng Aik Joo (Dr) is the Assistant Head of School from the School of Postgraduate Studies and course director in PSB Academy for MSc Engineering Business Management and MBA Global Business for Coventry University. He obtained his Professional Doctorate from Central Queensland University, Australia, specializing in Supply Chain and Logistics Management, Engineering Business Management and Global Business. His primary areas of interest include Understanding of the Artificial Intelligence, Research Methodology, Entrepreneurship, Global Lean and Agile Management, and Continuous Learning and Improvement Initiative. 